\title{
Water Diffusion Modelling of CFB Fly Ash Thermoset Composite
}

\author{
Ralph P. Villa ${ }^{1, a}$, Herbie T. Bella ${ }^{1}$, Julian S. De Lara ${ }^{1}$ and Romelando R. Juanatas ${ }^{1}$ \\ ${ }^{1}$ Department of Chemical Engineering, University of the Philippines-Diliman, Quezon City 1101 Philippines
}

\begin{abstract}
The shift in coal-fired power plants from pulverized coal (PC) boiler technology into the greener circulating fluidized bed (CFB) boiler technology resulted into a major deviation in the properties of the waste fly ash generated making it less suitable for its previous application as additives for construction materials. A new market for CFB fly ash had to be found for it not to end up as a zero value by-product. Using CFB fly ash as filler for thermoset composites is a new and remarkable application. Only a few studies, however, have been done to characterize the properties of this new material. Further experimentation and analysis may be costly and time-consuming since common procedures are material destructive. A computer-aided modeling of the composite's water sorption behavior was done. The effect of particle loading, size and shape were considered. These properties were varied and the resulting overall diffusivities were compared to previous experimental studies. The comparison of the model and experimental diffusivity values showed satisfactory results. This model may then provide a cheaper and more timeefficient method for the characterization of the water sorption properties of CFB fly ash thermoset composites. In the future, this may lead to further studies on its application as a green material.
\end{abstract}

\section{Introduction}

The shift of the technology used in coal-fired power plants from pulverized coal (PC) boiler technology into circulating fluidized bed (CFB) boiler technology had caused major changes into how the fly ash generated from the plants have been utilized over the years. Fly ash particles from coal-fired power plants were usually sold to cement companies and were used as an additive or filler to their building materials when the PC boiler technology was still in use. Now that the shift was made into CFB boiler technology due to its more promising energy conversion and it being more environmentfriendly because of less emissions, the fly ash generated are of different physical and chemical properties which caused it to be unfit for its previous applications [1]. Cement companies used to be the market for fly ash residues from power plants but with this change, a new market had to be found and established.

The proceedings of the 15th International Conference on Fluidized Bed Combustion presented how CFB fly ash could be helpful in construction usages but high chlorine content, the lack of the existence of free lime in the ash and the need for ash pretreatment had caused limitations to its applications in the construction industry. The nonuniformity in the size and the shape of the fly ash particles and the high sulfur content also proves CFB fly ash inadequate for use as a cement additive [2]. Given that all coal-fired power plants will eventually shift to the new technology and that the fly ash they produce will not anymore be used by the cement industry in the Philippines for their products, the problem on how to

\footnotetext{
${ }^{\mathrm{a}}$ Corresponding author: ralph.villa@coe.upd.edu.ph
}

dispose of or utilize these particles arises. Putting large amounts into landfill has become the most common method for handling CFB ash. Incineration and/or thermal degradation for the treatment of CFB fly ash also prove to be very expensive and therefore uneconomical. With the current trends in treating CFB fly ash and while putting economics into consideration, it is imperative to focus on developments through which these fly ash particles could be put to use. One possible use of the CFB fly ash is as fillers to polymer composites.

Studies to determine the properties of CFB fly ash particle-filled polymer composites or any new material can be done in the laboratory by making samples. This is feasible but can also be expensive given that several tests done to determine a material's properties are usually destructive and so the necessity of creating more and more samples for the results to be considered reproducible. An engineering breakthrough would be to create a nondestructive test (NDT) for material testing. One NDT technique that can be explored is the development of a predictive model for material property prediction.

The effect of particle loading, temperature and surface treatment on the moisture absorption of CFB fly ash reinforced polyester composite was recently studied by Onishi (2015) [3]. The effect of particle-filler shape on the moisture behavior through a different composite was also recently studied by Pajarito et.al. (2014) [4]. Modeling water diffusion through polymer composites are usually done by Finite Element Method (FEM) as shown in various literature [5-7]. In some, non-isothermal 
diffusion is also also studied using FEM as shown in the work of Yoon et.al, (2007) [8].

In this study, the isothermal diffusion of water through a CFB fly ash thermoset composite will be modeled using FEM. The effect of the filler fraction, filler shape and size distribution on the diffusion behavior will also be studied. A predictive model for the prediction of effectivity diffusivity of the composite will be formulated via regression analysis.

\section{Methodology}

\subsection{Simulations on pure resin}

To run the diffusion simulations, the student edition of the software ABAQUS was used. To simulate mass diffusion, $\mathrm{ABAQUS}$ requires the equilibrium moisture content and diffusivity of the material [9]. The pure properties of the resin were obtained from Onishi 2015 experimental results [3]. A sample, as seen in Figure 1, was drawn in the ABAQUS interface. The sample had a length of $2 \mathrm{~mm}$, and a height of $0.04 \mathrm{~mm}$. The size used was based on the size of the samples in the actual experiment. The length of $2 \mathrm{~mm}$ represents the thickness of the samples wherein the diffusion is assumed to occur in. The whole height of the sample was not used as it was assumed that a small slice is sufficient enough to model the diffusion that is assumed to occur uniformly throughout its length.

Figure 1. Resin Sample as seen on ABAQUS

As for the boundary conditions, both left and right sides of the sample were assumed to have a mass concentration of 1 with the water flowing through the $\mathrm{x}$ axis during the diffusion process.

The time period for the simulation was set at 25020 minutes, the same time period used in the actual experiment.

A triangular mesh was used in the FEM Analysis (Figure 2). The fineness of the mesh was limited by the software as it was just a trial version for academic purposes. The finest mesh possible was used.

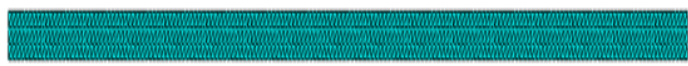

Figure 2. Representation of the Mesh used during simulation

Results of the simulation were then compared to the experimental results as well as the analytical solution to the Fickian Model of Diffusion.

\subsection{Obtaining filler diffusion properties}

To completely model the diffusion of water through the composite, the sorption properties of the filler must also be specified. However, no such properties were obtained from experimental data.

In order to obtain these properties, parametric studies were conducted by varying the diffusion and equilibrium moisture content one-at-a-time.

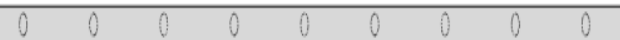

Figure 3. Composite RVE as seen in ABAQUS

Samples were made of the same size as the one for the pure resin. The average particle size of the fly ash used in the experiment were used in constructing the RVE. Fillers were arranged in a uniform, periodic manner. Fly ash volume concentrations of $4.82 \%$ and $23.28 \%$ were used. Figure 3 shows a sample used in the parametric study.

\subsection{Simulation run}

For the simulation run, a 3-factor, 2-level full factorial $\left(2^{3}\right)$ design of experiment was used [10]. The factors considered were volume fraction, filler shape, and particle size.

For this research, a two-dimensional drawing was used. The volume fraction was defined as the ratio of the area occupied by the filler and the area occupied by the resin. The filler shape was quantified by defining the ratio between its vertical length and horizontal length. Meanwhile, the particle size is defined by the horizontal length of the filler.

The following table summarizes each run.

Table 1. Summary of Simulation Runs

\begin{tabular}{|c|c|c|c|}
\hline Run & $\begin{array}{c}\text { Volume } \\
\text { Fraction }\end{array}$ & Shape & $\begin{array}{c}\text { Particle } \\
\text { Size }(\mu \mathrm{m})\end{array}$ \\
\hline 1 & 0.04815 & 0.8 & 15.3 \\
\hline 2 & 0.04815 & 0.8 & 33.3 \\
\hline 3 & 0.04815 & 1 & 15.3 \\
\hline 4 & 0.04815 & 1 & 33.3 \\
\hline 5 & 0.23285 & 0.8 & 15.3 \\
\hline 6 & 0.23285 & 0.8 & 33.3 \\
\hline 7 & 0.23285 & 1 & 15.3 \\
\hline 8 & 0.23285 & 1 & 33.3 \\
\hline
\end{tabular}

As with the previous procedures, the fillers were drawn in a uniform periodic manner, and the sample had a length of $2 \mathrm{~mm}$ and a height of $0.04 \mathrm{~mm}$.

The time period for each run were based on the actual time period used in the experiment, in all cases, 25020 minutes.

For the boundary conditions, the left and right side of the filler were set to have a mass concentration of 1 during the diffusion process.

Two responses are expected for each run, the effective diffusivity of the composite and the equilibrium moisture content of each.

\subsection{Statistical analysis}

Results of the diffusion simulations were then input in Design Expert, which conducts the regression analysis and ANOVA or analysis of variance. ANOVA is done to determine which of the three factors considered significantly affected the response variables.

Validation of the model was done by comparing its results to the experimental results. 


\section{Results and Discussions}

\subsection{Determination of resin and composite diffusion parameters from experimental data}

The Fickian model of diffusion, equation (1) [11], was fitted to experimental results obtained from Onishi (2015) [3] to determine the diffusion parameters, diffusivity D and saturated moisture content, $\mathrm{M}_{\infty}$ of the pure resin and of the composite. These values are to be used for the validation of the predictive model for the prediction of the effective diffusivity of the composite as well as input in the FEM modeling of diffusion.

$$
\frac{M_{t}}{M_{\infty}}=1-\frac{8}{\pi^{2}} \sum_{n=0}^{\infty} \frac{1}{(2 n+1)^{2}} \exp \left(\frac{-(2 n+1)^{2} \pi^{2} D_{\chi} t}{l^{2}}\right)
$$

Where:

$\mathrm{M}_{\mathrm{t}}$ is the moisture uptake at time $\mathrm{t}$

$\mathrm{M}_{\infty}$ is the moisture uptake at $\mathrm{t}=\infty$

1 is the specimen thickness

Equation (1) is obtained by:

$$
M_{t}=\int_{o}^{l} c(x, t) d x
$$

Where $\mathrm{c}(\mathrm{x}, \mathrm{t})$ is the solution of the Fick's $2^{\text {nd }}$ law [11]:

Where:

$$
\frac{\partial c}{\partial t}=D \frac{\partial^{2} c}{d x^{2}}
$$

$c$ is the moisture concentration,

$t$ is the time

$D$ is the diffusivity through the thickness

$x$ represents the thickness dimension

Subject to the following boundary conditions

$$
\begin{gathered}
c(0<x<l)=c_{0} \\
c(0, t)=c_{1} \\
c(l, t)=c_{1}
\end{gathered}
$$

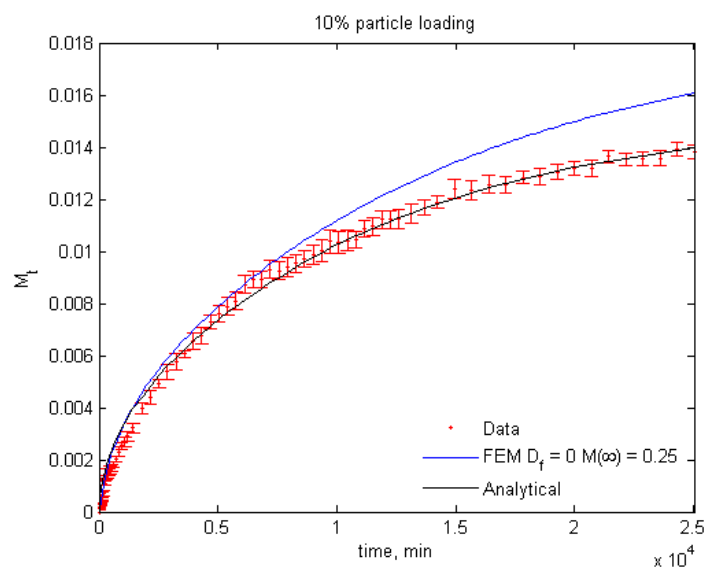

Figure 4 Sample Experimental results fitted with Fickian and FEM Model

Fitting the experimental data to the Fickian Model was performed using the lsqcurvefit command of MATLAB. Figure 4 shows the sample fitting of moisture content-time experimental data with the fickian model for a particle loading of ten weight percent. The comparison of experiment with the FEM model is only shown in the same figure (Figure 4).

The graphs above indicate that Fickian diffusion is a valid mechanism to describe the diffusion of water through a thermoset CFB fly ash composite.

The diffusion parameters were also determined at different filler loading conditions as shown in Table 2.

Table 2. Experimental Resin and Composite Diffusion Parameters

\begin{tabular}{|c|c|c|}
\hline $\begin{array}{c}\text { particle loading } \\
\text { [vol fraction] }\end{array}$ & $\begin{array}{c}\mathrm{D} \\
{\left[\mu \mathrm{m}^{2} / \mathrm{min}\right]}\end{array}$ & $\begin{array}{c}\mathrm{M}_{\infty} \\
\text { [wt. Fraction] }\end{array}$ \\
\hline 0 & 47.69364997 & 0.010742137 \\
\hline 0.048151333 & 42.90478368 & 0.015245192 \\
\hline 0.102189781 & 17.21908693 & 0.02444381 \\
\hline 0.163265306 & 2.288066141 & 0.084700255 \\
\hline 0.232848233 & 3.862657302 & 0.090250862 \\
\hline
\end{tabular}

\subsection{Predictive model for effective composite diffusivity}

A $2^{3}$ factorial design matrix (Table 3 ) consisting of particle loading, particle shape and particle size as factors and the composite diffusion parameters $\mathrm{D}$ and $\mathrm{M}_{\infty}$ as the response was implemented to develop a predictive model to determine the composite diffusion parameters from only the filler properties.

Table 3. $2^{3}$ Factorial Design Matrix

\begin{tabular}{|c|c|c|c|c|c|}
\hline Run & $\begin{array}{c}\text { Volume } \\
\text { Fraction } \\
(\varphi)\end{array}$ & $\begin{array}{c}\text { Shape } \\
(\mathrm{S})\end{array}$ & $\begin{array}{c}\text { Particle } \\
\text { Size } \\
\left(\mathrm{D}_{\mathrm{p}}\right)\end{array}$ & M_infinity & $\begin{array}{c}\text { D_effect } \\
\text { ive }\end{array}$ \\
\hline 1 & 0.04815 & 0.8 & 15.3 & 0.03007 & 28.249 \\
\hline 2 & 0.04815 & 0.8 & 33.3 & 0.01658882 & 26.479 \\
\hline 3 & 0.04815 & 1 & 15.3 & 0.02585 & 28.922 \\
\hline 4 & 0.04815 & 1 & 33.3 & 0.01610 & 25.275 \\
\hline 5 & 0.23285 & 0.8 & 15.3 & 0.09839 & 2.8751 \\
\hline 6 & 0.23285 & 0.8 & 33.3 & 0.03470 & 9.4096 \\
\hline 7 & 0.23285 & 1 & 15.3 & 0.10334 & 3.4984 \\
\hline 8 & 0.23285 & 1 & 33.3 & 0.05163 & 3.2123 \\
\hline
\end{tabular}

The three factors mentioned above was used to vary the representative volume element element (RVE) in the FEM analysis of diffusion of water through the composite. FEM results give the curves corresponding to (1). Equation (1) is then used to determine the corresponding diffusion parameters (also shown in Table 3).

Using the Design Expert software, regression analysis of the design matrix yield the following empirical models for the prediction of the diffusion parameters of thermoset CFB fly ash composite as a function of particle properties:

$$
\begin{gathered}
D_{\text {effective }}=33.09312-121.72837 \phi \\
M_{\infty}=0.00862016+0.60678 \phi+ \\
0.000021972 S+0.013861 \phi S
\end{gathered}
$$

The models above show that only particle loading significantly affects the diffusivity of the composite while the moisture content is affected by particle loading and particle size. 


\subsection{Validation of models}

Equations (4) and (5) were validated by comparing predicted values with those obtained from experiment (Table 2). The validation results are shown below in Figure 5 and Figure 6.

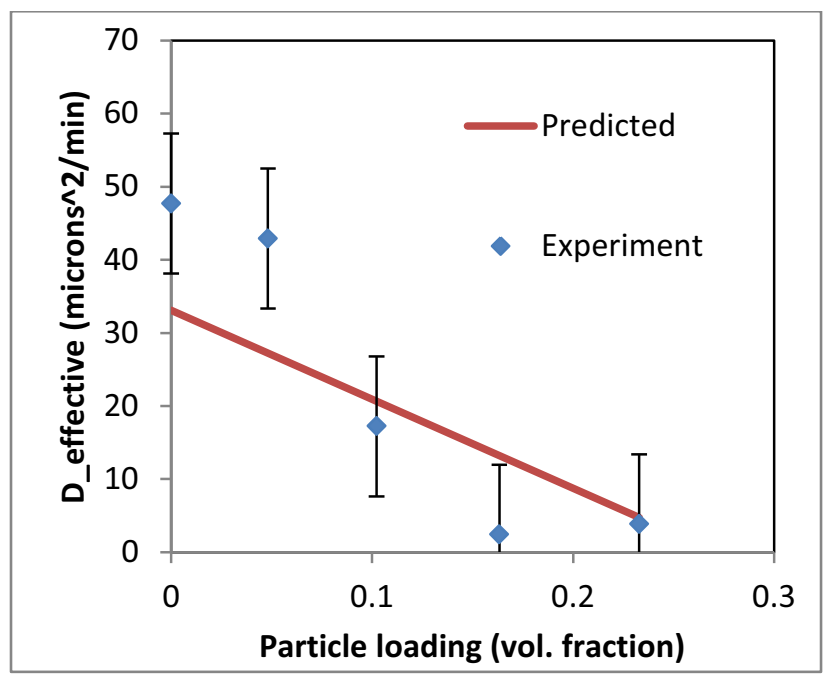

Figure 5 Predicted Diffusivity versus Experiment

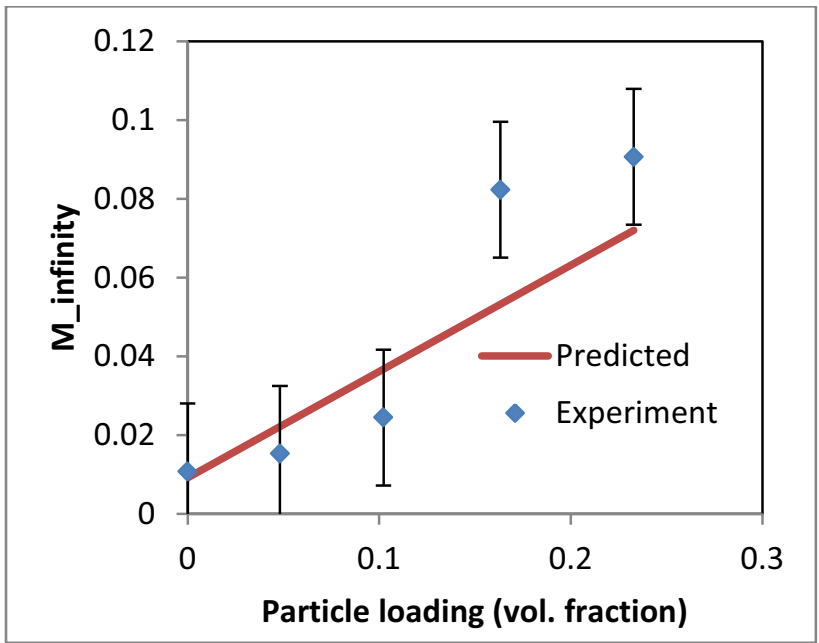

Figure 6 Predicted Saturation Moisture versus Experiment

\section{Conclusion}

A predictive model for the water sorption behavior of a CFB Fly Ash Thermoset composite was developed using Finite Element Method (FEM) and regression and analysis. The model was validated with experimental data and it was shown to fit satisfactorily.

From the model, it is also seen that only the volume fraction of the CFB fly ash in the composite had a significant effect in characterizing the sorption behavior of the composite. The equilibrium moisture content of the sample was also found to be affected mainly by the volume fraction of the CFB fly ash composite. An interaction between the volume fraction and the particle size also had a significant effect in the moisture content. Smaller particle size with the same volume fraction had caused a slight increase in the moisture content of the sample.

Results suggest that material properties of composites e.g. diffusivity can be easily determined by just knowing the filler's loading content and using an appropriate model. This validates the claim that a nondestructive test for material properties determination is a viable alternative to conventional destructive experimental techniques.

\section{References}

1. J. Utt and R. Giglio, Industrial Fluidization South Africa (2011)

2. R. E. Conn, K. Sellakumar, and A.E. Bland, Proceedings of the $15^{\text {th }}$ International Conference on Fluidized Bed Combustion (1999)

3. S. E. Onishi, Int. J. Chem. Eng. \& App., 6 (2015)

4. B. B. Pajarito, M. Kubouchi, and S. Aoki, J. Mat. Sci, 37 (2014)

5. J. Yang, Q. Yang, L. Ma, and W. Liu, Front. Mech. Eng. China, 5 (2010).

6. Y. Joliff, L. Belec, and J.F. Chailan, Comp. Struc., 97 (2013)

7. L. Canal and V. Michaud, Comp. Struc., 111 (2014)

8. S. Yoon, B. Han, and Z. Wang, JEP, 129 (2007)

9. ABAQUS 6.13, Analysis User's Manual, Sec 6.9

10. D. Montgomery, Design and Analysis of Experiments (John Wiley \& Sons, Inc., 2013)

11. J. Crank, The Mathematics of Diffusion (Clarendon Press, England, 1975) 